\title{
Pragmatics of Understanding: Centrality of the Local
}

\section{Cases from Japanese Discourse and Alzheimer's Interaction}

\author{
Yoshiko Matsumoto \\ Yamato Ichihashi Professor in Japanese History and Civilization, \\ Department of East Asian Languages and Cultures and, by courtesy, \\ Linguistics, Stanford University, Stanford, CA, United States \\ yoshikom@stanford.edu
}

\begin{abstract}
Cross-cultural contrastive approaches motivate research that questions the universality premise of pragmatic theories by illustrating facts of local linguistic practices from diverse geographical areas. In the spirit of my earlier studies of Japanese (e.g. Matsumoto 1988, 1989), I suggest that contrastive pragmatics can lead the field of pragmatics to addressing variations in linguistic practice that go beyond the geographical diversity of cultures and encompass other types of "atypical" discourse, such as discourse of speakers with varied cognitive conditions including persons with Alzheimer's. This paper argues for the PRAgmatics of UNDERSTANDING, i.e. the language users' and the analysts' efforts (i) to understand what speakers are trying to convey in verbal interaction and (ii) to understand local pragmatic principles of verbal exchange, and thereby to encourage more inclusive studies of pragmatics.
\end{abstract}

\section{Keywords}

pragmatics of understanding - Japanese discourse - Alzheimer's discourse - Gricean logic of conversation

As numerous studies in contrastive pragmatics have made clear, the investigation of seemingly equivalent linguistic expressions or comparable pragmatic 
acts affords a refined and nuanced understanding of how specific languages are used in context. Cross-cultural contrastive approaches also motivate research that problematizes the universality premise of pragmatic theories by illustrating facts of local linguistic practices from diverse geographical areas, especially those outside of the Standard Average European languages (SAE $).^{1}$ Locally found phenomena may be viewed as atypical and peripheral in contrast to those placed in the center in universal theories, but they are invaluable, as they offer the possibility of uncovering unnoticed yet crucial pragmatic aspects of verbal communication. They ultimately encourage more inclusive studies of pragmatics. This paper suggests that this endeavor should be extended to include investigations of communication by people with varied cognitive conditions, such as persons with dementia.

\subsection{Related Previous Studies}

It is perhaps not surprising that theoretical explorations in seeking universal principles focus on what are assumed to be typical or core phenomena. Gricean principles of conversation (e.g. Grice 1975), speech act theory (e.g. Austin 1962, Searle 1969, 1975) and universal theories of politeness phenomena (Brown and Levinson 1978, 1987) are classic examples. These theories have been regarded as the analytical benchmarks for pragmatic investigations of many languages, even though they were rooted in the Anglo-American philosophy of language (e.g. Huang 2017) and accordingly based on presuppositions of what is the normal or expected content of an (unmarked) utterance in English. Although they used examples from non-European languages, Brown and Levinson $(1978,1987)$ proposed their theory of politeness to provide an explanation for why divergences from Gricean Maxims occur in conversation, thus tying the theory to the cultural and linguistic domain of ordinary English language investigated by Grice. ${ }^{2}$

On the other hand, there have been studies that found local facts that were not accounted for by the respective universal theories. Early work in this regard include Keenan (1976), who contrasted speech patterns of Malagasy speakers against Grice's Maxims and questioned specifically the assumption behind the Quantity Maxim, and Silverstein (1976), who, drawing examples from a variety of languages including Thai, Javanese, Native American languages, and Australian languages, argued for the criticality of indexical meanings of linguistic elements beyond the referential and propositional meanings,

1 See Whorf (1956 [1941]), Haspelmath (2001) for the use of the term in linguistic typology.

2 See Matsumoto $(1988,1989)$ for more detailed discussions, and Ameka and Terkourafi (2019), who provide similar views with recent references. 
traditionally central in universal theories. Rosaldo (1982) challenged the universality of speech act theory through Illongot speech practices; Wierzbicka (1986) called attention to cultural variability in reference to Australian English; and Matsumoto $(1988,1989,2003)$ illustrated with examples from Japanese, in contrast to the premise of Gricean principles and Brown and Levinson's universal politeness theory, that relational information beyond the denotational and propositional content conveyed in verbal interactions is an inextricable part of the language and that such patterns of communication require understanding of local diversities and theoretical flexibility in describing conversation and politeness. Similar points are advocated in recent studies (e.g. Ameka and Terkeroufi 2019, Kádár and Haugh 2013, Levinson 2012, Wierzbicka 2014), indicating the importance and need for even more studies inclusive of diverse linguistic and cultural practices from a wide variety of geographical regions.

\section{$1.2 \quad$ Current Study - Pragmatics of Understanding}

In the spirit of my earlier studies of (e.g. Matsumoto 1988, 1989), I suggest in this paper that contrastive pragmatics can lead the field of pragmatics to addressing variations in linguistic practice that go beyond the geographical diversity of cultures and encompass other types of "atypical" discourse such as discourse of speakers with varied cognitive conditions including persons with the Alzheimer's, the most common type of dementia. My main aims of this paper are to argue for the PRAgMatics of Understanding, i.e. the language users' and the analysts' efforts (i) to understand what speakers are trying to convey in verbal interaction and (ii) to understand local pragmatic principles of verbal exchange, and to encourage more inclusive studies of pragmatics.

As I described previously, the structure and the practice of Japanese reflect sensitivity to a variety of relations in interaction, e.g. relations among the participants in the described event and among interlocutors, as well as the relation of the speaker and of the discourse to the textual and social context. However, from the perspective of the purportedly universal theories mentioned above, which focus on the evaluation and calculation of the denotational information of what is said, the relational information is not perceived to be essential. From that viewpoint, the linguistic practice and principles of Japanese could be regarded as atypical or orthogonal to the theoretically considered phenomena and as needing reevaluation and reinterpretation.

The discourse by persons with dementia is also viewed as atypical as such persons are considered to have lost much of their communicative ability as a result of cognitive impairment caused by the medical conditions. To be sure, 
the production of speech of persons with dementia often appears to be compromised in comparison to adults without dementia, and their conversations may not share the underlying assumption of Grice's Cooperative Principle that "the purpose of talk exchange is a maximally effective exchange of information" (Grice 1975). However, as I will illustrate in this paper through a case study of conversations in English by persons with Alzheimer's, the speech of such persons indicates that they retain much of their communicative competence and that they can communicate among themselves in a variety of situations. Once we disengage our analysis from the assumptions behind Grice' logic of conversation, for example, and pay attention to contextual and relational factors of the interaction similarity to the factors relevant to Japanese interaction, the retained pragmatic competence of persons with Alzheimer's becomes more apparent.

The juxtaposition of ordinary Japanese linguistic behavior with dementia communication in English may seem odd at first. Indeed, the discussion in this paper is by no means intended to equate the Japanese language and practice with the English of persons with dementia. However, I hope that it will become clear that the Japanese perspective helps to understand the pragmatics of Alzheimer's discourse and that the two discourse practices are comparable in that the relational aspect of language use is essential to communication in each. Further, both exemplify local practices that challenge the common premises of the conventional pragmatic principles.

To give the background for the verbal interaction involving persons with dementia, I will revisit in section 2 the importance of the relational aspect of verbal exchange in Japanese practice with some examples. Section 3 provides a brief introduction to the discourse of individuals with dementia. In section 4 , a case study of interactions involving persons with Alzheimer's based on a documentary film that chronicles the daily interactions of residents in a memory care center in the U.S. is given. I will consider how different types of interaction influence the communicative output of individuals with dementia. The conclusion in section 5 extends the implications of the study.

\section{Relational Aspect of Verbal Exchange - Background from Japanese Discourse}

In this section, I will review briefly how relational aspects of verbal interaction are integral to Japanese practice with a few representative examples. As I noted elsewhere (Matsumoto 1989), the discrepancy between Japanese 
practice and the conventional universal theories is attributable to the type of information that is necessarily conveyed in a Japanese verbal exchange. As social and psychological attitudes, or affect, are indexed in Japanese lexical items and phrases, we cannot ignore such relational aspects of informativeness which is outside of the factual or propositional informativeness that the Gricean paradigm takes into consideration. At the same time, referential expressions that are required in English in the positions of arguments (e.g. subject, object) are often inexplicit in Japanese, making the construal depend on semantic and pragmatic information accessible from the linguistic and nonlinguistic context and prior background knowledge (e.g. Clancy 1980, Matsumoto 1997, 2017). There are many ways in which relational aspects of language use can be indicated in Japanese, but I will touch upon a few instances of the two points I just mentioned above; namely (1) the interpersonal relation and (2) textual and contextual relations.

The interpersonal relation can be expressed by what I called "relationacknowledging devices" (Matsumoto 1988), such as formulaic expressions, honorifics and verbs of giving and receiving. They index the interlocutors' psychological and social relationship inseparably from the denotational meanings. The following excerpt (1) presents an example. The conversation shows different forms of the verb that means 'said' (i.e. itteta, ittemashita, itteirashita), which index different relationships among the relevant interlocutors and to the context, while the propositional content of the utterances in lines 2 and 3 is exactly the same, i.e. '(they) said so.'

(1) Conversation among amateur singers

1 Yuri: ( ) okaasama suteki datta deshoo tte ( ) ittara, anoo.

2 Emi: $\operatorname{soo}()$ ittetayo

3 Yuri: soo ( ) ittemashitayo, Г soo ( ) itteirashita wa ee.

4 () sutekidatta tte nee.

5 Aki:

L a soo.

English translation:

1 Yuri: When (I) said, '(your) mother.H on was fabulous, wasn't she?', umm

2 Emi: (She=Yuri / THEY=MIE's CHILDREN) said so.

3 Yuri:(They) said.Performative.Honorific so, Г(they) said.Referent.Honoric so, yes,

$4 \quad$ (they said that) (you) were fabulous, right?

5 Aki: $\quad L$ is that so. 
The word itteta, '(she/they) said' in line 2 indicates a straightforward description of the event and of the speaker's relation to the addressee. But, the two versions of the same proposition '(they) said so' in line 3 indicate more nuanced stances; ittemashita is more distant and formal than itteta, and itteirashita indicates that the speaker treats the subject referent of the verb 'said' as elevated, while indicating less distance from the addressee than ittemashita. To add a brief background, this excerpt is from a tape-recorded casual conversation among a group of middle-aged female amateur singers who just held a concert together. In the excerpt, Yuri compliments the performance of one of their solo singers, Mie, by reporting Mie's children's positive response to her performance. Yuri's use of the verb form itteirashita, which elevates the referent of the subject (Mie's children) in line 3, is not pre-determined by any measure but is indicative of personal view. The variation in repeating the same factual content shows that the essential information Yuri (the speaker) wanted to convey is interpersonal rather than propositional. This and other similar examples suggest why attention to relational and interactional aspects of verbal exchanges forms a significant part of pragmatic analysis of Japanese. An individual's pragmatic competence includes more than the adherence to Gricean maxims or the use of implicatures derived from the propositional content of utterances, and this point is equally important to understanding the pragmatic capabilities of persons with Alzheimer's.

Example (1) also presents the second relational aspect, i.e., the textual and contextual relation, which is important in Japanese verbal interaction. The excerpt(1) shows thatreference can often beinexplicit(as indicated by the empty parentheses in Japanese) and that referents need to be construed from the linguistic and nonlinguistic contexts and from the background knowledge. Potential ambiguity is well tolerated (Clancy 1980:166) as shown in the differing potential translations in line 2. This ambiguity from the point of the listener (such as Aki or Mie) is likely to be resolved while hearing the later utterance by Yuri.

Ambiguity can sometimes be unresolved by both the speaker and the listener, especially when the exact referents are not crucial to the understanding of what is conveyed in the conversation. As the English translation of (2) suggests, the exact identification of inexplicit referents can be left ambiguous or indeterminate without causing a problem in a conversation. The first speaker, $\mathrm{Kazu}$, is an instructor of Japanese at a U.S. university and is fully knowledgeable about the situation of Japanese language instruction in Japan, the topic of the conversation. Nevertheless, the speaker himself could not provide the particular identity of the inexplicit reference when I later asked him to identify 
it. When the exact identity of the participants in the described event or state does not have essential bearing on the intent of the utterance, the speaker may not feel the necessity of specifying it and the listeners may accept it as indeterminate.

(2) A Japanese language instructor's view about teaching Japanese

1 Kazu: de:... nihon e () ittara sa ...

2 Tomo: un

3 Kazu: () genbun-shugi de sa

4 Tomo: un

5 Kazu: dondon dondon sa

6 ... hontoni ... namano mono de () yondeiku tteyuu kanji n naru desho:

English translation:

1 Kazu: and ... if (students outside of Japan/people associated with Japanese language learning outside of Japan /non-specific) go to Japan

2 Tomo: uh-huh

3 Kazu: (Japanese teachers/a professional organization/etc.) have the principle of reading the originals

4 Tomo: uh-huh

5 Kazu: one after another

$6 \quad \ldots$ (students/teachers/students \& teachers) really seem to read things from the authentic text, right

Another example of how construal of Japanese depends on textual and contextual relations, i.e. semantic and pragmatic coherence, and less on explicit syntactic marking is illustrated by the noun-modifying construction in (3), uttered by a female speaker at an afternoon teatime. In this example, which is a perfectly comprehensible natural utterance in Japanese, okashi 'sweets' is modified by the preceding predicate clause futoranai ' $(\mathrm{X})$ does not get fat' just as in a relative clause construction, ${ }^{3}$ but in this and other instances of nounmodifying constructions in Japanese, there is no relative pronoun or any

3 Because Japanese is a head-final language, the modification precedes the head. The commonly used term, relative clauses, is not used here since general noun-modifying clause constructions (in Japanese and other languages) do not share the same restrictions as relative clauses. (For more discussions, see Matsumoto et al. 2017). 
other markings to indicate the grammatical relation of the head noun okashi 'sweets' to the content of the modifying clause ' $(\mathrm{X})$ doesn't get fat.' The subject of the predicate in the modifying clause is inexplicit, and it is semantically unlikely that it is okashi 'sweets.' The meaning of the construction is construed by understanding how the constituents, futoranai 'does not get fat' and okashi 'sweets,' cohere through the interpreters' knowledge of the meanings of the words and of the attendant expectations in the real world. (See e.g. Matsumoto 1997, Matsumoto et al. 2017 for more comprehensive discussions on nounmodifying clause constructions).

(3) Noun-modifying construction

[[Futor-anai $] \quad$ okashi $]$ wa nai $\quad$ kashira.
gain.weight-not sweets TOP exist.not $\quad$ I.wonder
'I wonder if there aren't any sweets (even though (X) eats which) (X)
doesn't get fat.'
'I wonder if there is a non-fattening candy'

The significance of the relational aspect of Japanese discourse as exemplified in (1)-(3) is also reminiscent of how the discourse of people with dementia has been described. Ellis (1996:472) describes that "[T]he discourse of Alzheimer's patients becomes pregrammatical in that it is vocabulary driven and reliant on meaning-based features of discourse rather than grammatically based features" and, pointing out the importance of focusing on the pragmatics of communication, states that "the burden of communicating with those who have Alzheimer's disease will increasingly fall on the nondemented partner" (491).

Although Japanese and Alzheimer's discourse are undoubtedly far from being equivalents, conversational data of persons with Alzheimer's discussed in the next section will reveal that they overlap in foregrounding relational information conveyed and construed in the verbal interaction, information that goes beyond the denotational meaning.

\section{Verbal Interaction of Persons with Dementia}

The verbal interaction of persons with dementia is often viewed as atypical and peripheral, relative to more commonly encountered interactions among people without dementia. It is also viewed as a target of study only for researchers 
specifically interested in discourse in healthcare or disability. However, as suggested in introduction, it presents broader implications for pragmatics research.

According to the Alzheimer's Association, dementia is "an overall term for diseases and conditions characterized by a decline in memory, language, problem-solving and other thinking skills that affect a person's ability to perform everyday activities. As of 2017, 5.8 million people in the U.S. are living with Alzheimer's, the most common cause of dementia." ${ }^{4}$ As the older population continues to grow in industrialized countries, the projected number of people with dementia will increase in the future, unless a cure is found.

In cognitive and clinical studies, focusing on the cognitive impairment associated with dementia, the linguistic behavior of persons with dementia tends to be represented from the point of view of pragmatic deficits and disorders. Cummings (2017), describing the advancement of clinical pragmatics, states that "the pragmatic turn in the study of communication disorders has had its most profound impact on the assessment and treatment of these disorders" (Cumming 2017:347). She points to findings that report reduced sensitivity to violations of Gricean maxims (Brownell and Stringfellow 1999; Surian and Siegal 2001) and difficulty with the comprehension of figurative language, the use of cohesion devices, and referential communication (e.g. Ripich et al. 2000, Papagano 2001). There are other studies that reported similar points. Kempler (1984:123), for example, observes that the discourse of people with dementia can be described as "impoverished, empty, and often irrelevant." Similarly, Dijkstra, et al. (2004) report "the higher occurrence of discourse deficits in discourse of adults with dementia, such as a higher occurrence of empty phrases, aborted phrases, indefinite terms, repetitions, referential cohesion errors, and disruptive topic shifts" (Dijkstra, et al. 2004:275). The unclear use of pronouns is often suggested as a significant source of difficulty in communication.

In contrast, studies that investigate interactions observed in the discourse of persons with dementia from the sociolinguistics and interpersonal approaches to pragmatics draw attention to the interactive perspective on the communicative abilities of individuals with dementia. Such studies have emphasized that the verbal abilities of persons with dementia are not simply determined by their cognitive conditions but are crucially influenced by their conversation partners' responses in the interaction and by attitudes toward the speakers (e.g. Hamilton 1994, Ramanathan 1997). In these and other interactionally focused studies, the preservation of communicative competence and

4 https://www.alz.org/alzheimers-dementia/what-is-dementia. 
reciprocity in interaction are highlighted (e.g. Ryan et al. 2005) and the skillful use of discourse markers is discussed (e.g. Davis 2005). These findings support the claim by Kitwood (1997) that the personhood of speakers with dementia is bestowed through interconnectedness and interdependence with the people who participate in the interaction. The investigation in this paper is consonant with these studies in that it draws attention to the interactional perspective of language use, an approach that is of particular importance when investigating atypical and local languages.

In their study of pragmatics in dementia discourse Guendouzi \& Davis (2013) wrestle with a divide between "mainstream theoretical pragmatics and applied research in communication disorders" and suggest creating a bridge between them by applying theory to clinical data while using data to validate theory. At the same time, they also point out difficulties in applying concepts from pragmatic theory, such as speech acts and the notion of inference, to explain conversational data of people with dementia. The difficulties may be explained by the different perspectives of pragmatic research. Not all uses of language and pragmatic phenomena are satisfactorily accounted for from the logical or cognitive perspectives that have dominated traditional pragmatic theories. For instance, Wray (2020: 73) points out that "hypercognitivity," the sentiment that "cognitive enhancement defines our dominant image of human fulfilment” (Post 2000:245), which pervades modern Western society, is a factor influencing the Western attitude toward dementia. Further, Perkins (2007) questions the practice of using Gricean Maxims as the standard, when that standard itself is not clear, by saying "although it is generally assumed in mainstream pragmatics that we are attempting to describe what typically occurs in the normal population, definitions of what counts as normal are rarely made explicit, if they are considered at all. [...] there is no account of how informative or uninformative a contribution would need to be to count as an instance of abnormal or pathological behaviour" (2007: 10-11).

The investigation in this paper will illustrate that a different perspective, the pragmatics of understanding, can lead to a more inclusive approach to human communication.

Case Study - Documentary Film: You're looking at me like I live here and I don't

The analyses of the discourse by individuals with dementia in this paper are based on the interactions documented in an award-winning film entitled You're 
looking at me like I live here and I don't (2010) directed by Scott Kirschenbaum. ${ }^{5}$ A crucial feature of this 64 minute documentary film is that, except for a few questions that the filmmaker asks, it comprises only the spontaneous interactions of the residents and care workers observed in a memory care unit at an assisted living center in the United States, ${ }^{6}$ and is void of narration. The camera follows one woman, Lee, who was 79 years old with moderate-stage Alzheimer's disease at the time of filming. Lee has worked, raised a family, and has grandchildren. Although the film focuses only on one person in one facility, it provides naturalistic documentation of the experience of one person with dementia and the daily interaction of people who live and work there.

The film shows considerable interactional communication among the residents and with the care workers, contrary to the common perception that there is a serious communication breakdown among people with dementia. Interactions that are anchored in familiar quotidian experience and in the associated affect especially seem to enable individuals with dementia to maintain functionality in communication through stages of dementia. These observations from the film, as will be elaborated in this section, generally support the findings of previous studies from the interactional perspective $-v i z$. that (i) communicative competence is substantially preserved among persons with dementia (e.g. Kitwood 1997, Davis 2005, Ryan et al. 2005); (ii) what is fundamental to meaning-making is interaction (e.g. Hamilton 1994, Ramanathan 1997); and (iii) interaction is crucial in maintaining the well-being of people with dementia (e.g. Kitwood 1997, Dijkstra et al. 2004, Davis et al. 2005).

Notwithstanding the general point on the preservation of communication competence, it is also true that some (but not all) of responses of Lee, the main character in the film, to certain information-seeking questions can be difficult to comprehend from the point of view of common expectations for conversations of speakers without dementia. Interlocutors who hold expectations consonant with the Conversational Principle proposed by Grice (1975) and its four attendant conversational Maxims know that when a speaker flouts one or more of the Maxims, the speech will convey an implicature. Some utterances of speakers with Alzheimer's can be interpreted as violations of Maxims in contexts where there is no apparent intention to imply additional meaning - that is, where there is no intended implicature. Such violations without intended implicature would normally be seen as infelicitous, if not incomprehensible.

5 A DVD of the film is available for purchase at https://yourelookingatme.com/index.html. It was premiered in 2012 as an episode in the Independent Lens program of the Public Broadcasting Service, U.S.A.

6 The filming team allocated about six months for preparation, visiting the center and getting to know the residents and the care workers there, and spent approximately eight hours a day for 10 days for the actual filming (Kirschenbaum, personal communication). 
Following this reasoning, the clinical pragmatics studies mentioned above conclude that individuals with dementia reveal their neurological impairment through showing difficulty adhering to these rules.

What is seen in the discourse of Lee and other residents in the memory care facility depicted in the documentary film, as we consider more closely in sections 4.1-4.3, provides us with a more nuanced understanding of the pragmatic competence of persons with dementia and motivates the adaptation of multiple perspectives in the study of pragmatics. The performance by persons with dementia varies depending on the interactants, the purpose and the content of interaction. For example, when being asked information-seeking questions based on factual knowledge unconnected to the immediate context, Lee does not respond in the way that satisfies logic-based pragmatic expectations. In contrast, when conversations reference interactionally and interpersonally important experiences, Lee participates in the interaction effortlessly with expressions of gratitude, humor, or personal opinions. Her conversations with care workers and with her fellow residents provide instances of successful interactionally-based communication while her interaction with the filmmaker show some communication failures in factual-based questions unrelated to the conversational context. Lee's responses to factual-based questions sometimes do not immediately address the point of the question at issue when she has difficulty responding. But it is clear that she attempts to respond, and that act evidences her contextual and interactional understanding of what her interlocutor's previous utterance requires. We will see examples of this type in Lee's conversations with the filmmaker in 4.1.

Other residents with varied degrees of dementia also produce interactive and communicative responses regardless of whether they are sharing their complex life stories or exchanging simple verbal and nonverbal affect-laden comments. The partners of Lee's interaction in the examples are the filmmaker, Scott, who asks a few questions off-screen to Lee, the care workers, and fellow residents. The following sections examine instances of Lee's interaction with these partners and interactions among other residents. The sections are divided according to the interactants and type of interactions, but discussions will also pay attention to the two relational aspects (interpersonal and textual/ contextual) of exchange that we observed in the earlier section. The examples are accompanied by video clips, which present multimodal information in addition to the transcripts.

\subsection{Questions Asked by the Filmmaker to Lee}

There are a few scenes in the film in which the off-screen filmmaker asks short questions to Lee in the style of an interview. His questions are not heard but are easily inferred from Lee's responses. In the excerpt given in (4), 
he apparently asked Lee: What is your favorite color? This is one of the questions relatively common in the U.S. as a way to get to know a person, just like asking about favorite books or places. For that reason, it is often asked out of the blue without any context associated with color, and that is how it is asked in the film. Lee has trouble answering it and does not mention any color term. ${ }^{7}$ The excerpt given in (4) illustrates the difficulty that Lee experiences in attempting to respond to a conceptual question that is not contextually or emotionally supported.

(4) Response to fact-finding question ("What is your favorite color?"): Not relevant to immediate context or emotion [video clip 1] <https://doi .org/10.6o84/mg.figshare.13124483>

1 Lee: what is MY favorite color

2 oh lordy lordy lordy what did I get into

$3 \quad$ ah $(\ldots)$

4 three four threes? < accompanied hand gestures>

$5 \quad$ and THAT isn't an easy one? < accompanied hand gestures>

$6 \quad$ 'cause I usually (.)

7 THEY can THEY'll come right in over here

8 'cause I'm not kind'f let person go

$9 \quad$ and say all right, th-

Lee's reply diverges from what is usually expected, e.g., a quick mention of a color term or saying that she does not have a favorite color. If the Gricean Maxims were straightforwardly applied, Lee's response would clearly violate the Maxims of Quantity and Manner without an obviously intended implicature. While it is recognizable that Lee intended to be relevant (Relation) to the question asked, her responses after line 3 would be judged infelicitous from the point of view of the discourse of non-dementia speakers. Lee's utterance could also be interpreted as a violation of maxim of Quality because she seems to evade answering. The extract (4), therefore, can be seen to exemplify reduced sensitivity to violation of the Gricean maxims, similarly to what was described in the studies in clinical pragmatics mentioned above. The uses of the demonstrative that in line 5 and the pronoun they in line 7 are unclear in terms of their referents in the given context, and they can be characterized as examples of referential cohesion errors and uses of indefinite terms, hindering a logical interpretation of the utterance.

7 This may also be influenced by the fact that semantic memory, which includes color terms, has been found to be affected by the Alzheimer's disease. 
On the other hand, Lee's pragmatic competence is indicated by the use of the possessive form of the first person pronoun my in line 1 (rather than simply repeating what Scott must have said, i.e. your). It shows that she understood that Scott asked a question about her and that the utterance required her response. The issue of clear reference in line 5 could be understood as a previously mentioned topic and that of line7 as ambiguous inexplicit reference that could be left to work out later, as it can be the case in some Japanese conversations. From Lee's response in line 2, oh lordy lordy lordy what did I get into, we can conjecture that she knew what was asked and realized that it was a difficult question to respond to. The impairment in memory ${ }^{8}$ and other cognitive disabilities caused by Alzheimer's must have affected Lee's ability to respond adequately, but she attempted to cover up that fact by continuing to talk. While this can be identified as a communicative problem, similar attempts to a lesser degree can also be taken by non-dementia speakers when they cannot instantly provide precise responses in order not to halt the conversation and save face of both participants. What excerpt (4) suggests, then, is that Lee shows difficulty in responding to a question about knowledge-based conceptual matter independent of the immediate situation, but her focus is to maintain the interactional and textual relation in the given context.

When the topic, although conceptual, involves emotion which Lee is likely to have personally experienced, as in (5), she not only responds to it, but her response is more specific.

(5) Response to fact-finding question (“What is love?"): Involving emotion [video clip 2] <https://doi.org/1o.6o84/mg.figshare.13124483>

1 Lee: love

$2 \quad$ (... approx. 5s)

$3<$ Licks lips for approx. 8s>

$4 \quad$ (... approx. 4s)

$5 \quad<$ inhalation>

$6 \quad<$ smiles slightly, nods for approx. 3s>

7 that's a damn good (..)

8 thing to work with

9 absolutely wonderful

10 the others get nasty

8 The role that memory plays in communication is vast and complex. See Wray (2020) for summary, especially in relation to dementia. 
As observable in the video clip, Lee shows more facial expressions in (5) than in (4), expressing her emotions according to what she thinks about love. Her utterances in the excerpt are more understandable to people without dementia than those in (4). Provided that defining 'love' is not an easy task for anyone with or without dementia, giving a relevant answer in about 20 seconds without prior preparation shows Lee's capacity to handle a topic involving her experienced emotion.

The next excerpt (6) is Lee's response to a question as to where her husband is. In contrast to the questioned in (4) and (5), the topic of (6) is more personally and emotionally relevant, as it is about Lee's late husband. Lee's response he died follows almost immediately in lines 3 and 4 after she rephrases the question (by changing your to $m y$ ) that Scott apparently asked. Lee's response to Scott's follow-up question "Do you miss you-your husband?" is also prompt and shows no sign of searching for words. Her non-verbal expressions (shown in the video clip) indicate that the slight pauses in lines 13 and 15 are indicative of her emotions toward her husband, not difficulty in responding.

(6) Response to fact-finding question ("Where is your husband?"): Involving intimate experience and emotion [video clip 3] <https:// doi.org/10.6o84/mg.figshare.13124483>

1 Lee: where is MY husband?

$2 \quad<$ inhalation $>$

$3 \quad$ HE died (..)

$4 \quad$ HE died

$5 \quad(\ldots 4 \mathrm{~s})$

6 it seems like

$7 \quad$ <shaking head, putting hands on temples>

8 what is the matter with you <releasing hands outwards $>$

$9 \quad$ (..) $S H E-[\mathrm{xxx}]-() T H. E Y^{\prime} \mathrm{re}$ okay,

10 THEY're not that bad,

$11 \quad(.$.

12 SK: do you miss (.) you-your husband?

13 Lee: $(.2 s)<$ slight smile, slight nods >

14 yes

$15 \quad(\ldots 2 s)$

16 yes

$17 \quad$ and I will all along

The pronoun he in lines 3 and 4 has a clear antecedent in this example. Between lines 6 and 10, the only point that may be noticeably different from utterances usually expected among non-dementia speakers is the lack of the 
clear antecedents of the pronouns she and they in lines 9 and 10. The cohesion of the utterances here may suffer for this reason. On the other hand, people who are familiar with the situation surrounding the death of Lee's husband and her family might be able to reconstruct the situation and understand the gist of Lee's utterances, accessing some background knowledge without the aid of clear reference in a similar way in which Japanese conversation partners try to construe utterances with inexplicit referents.

The three excerpts from interaction between Lee and the filmmaker of fact-finding questions illustrated that Lee's responses do not uniformly show signs of cognitive impairment. She responded to emotionally and personally relatable questions with more ease than a question without. She also understood the pragmatic requirement for the interactional context of question and response. What appear to be sought on the part of interactional partner is an effort to construe what the speaker tries to convey by mobilizing textual and contextual knowledge in the background. This importance of relational aspect of language use is reminiscent of Japanese discourse, as we discussed in the last section. From the perspective of logic-oriented pragmatics, the verbal ability of someone like Lee can be judged to be impaired, whereas from the perspective of pragmatics of understanding, concerning interactional aspects of human communication, the behavior demonstrates pragmatic competence. The following sections also present similar observations.

\subsection{Interaction between Lee and Care Workers}

Unlike the interaction between Lee and the filmmaker in the last section, conversations that Lee has with care workers in the film are about matters of daily life and the immediate situations in which they occur. We will consider three excerpts in this section, all of which exhibit humor and formulaic expressions including gratitude. The first conversation, given in (7), is taken in Lee's room when she is getting assistance from a care worker to put on earrings and lipstick and comb her hair to get ready before leaving her room. The care worker in (7) is probably assigned to Lee on a regular basis as she appears in other scenes, such as (8), closely interacting with Lee. The third excerpt, (9), is an exchange between Lee and workers at the dining room, where Lee starts a tongue-in-cheek interaction with them.

The excerpt in (7) flows naturally as a daily conversation and would be indistinguishable from a conversation between speakers without dementia. The label CW in the transcript stands for a "care worker."

(7) Immediate matters of daily life - Getting ready [video clip 4] $<$ https://doi.org/10.6o84/mg.figshare.13124483>

1 Lee: here $<$ Lee throws away something into a waste basket $>$ 
2 oh, I forgot to do something else, $<\mathrm{CW}$ is putting an earring on Lee $>$

3 sitting here like an idiot

4 (... approx. 4s)

5 CW1: there we go

6 Lee: oy vey

$7 \quad$ CW1: oy vey

8 Lee: oy vey, I don't know

$9 \quad$ (... approx. 7 s) $<$ Lee applies lipstick facing the mirror that $\mathrm{CW}$ holds up for her $>$

10 Lee: all right?

11 CW1: <nods $>$ perfect $<$ smile $>$

$12<\mathrm{CW}$ brushes Lee's hair, checks the look, then start walking away>

13 <Lee stops CW and kisses her on the cheek>

14 Lee: thank you

15 CW1: thank you $<$ smile $>$

Lee's utterances between lines 6 and 14 are comprised of well-placed formulaic expressions, such as oy vey, I don't know (with a stress on I and know), all right and thankyou, which are used commonly in ordinary conversations. The (Yiddish) interjection, oy vey, and the clause I don't know in lines 6 and 8 are interpretable as comments about what Lee referred to in her utterance in lines 2 and 3 , the fact that she forgot to do something else. It is interesting to note that the care worker uses expressions similar to those Lee commonly uses, such as oy vey and perfect (which Lee says often in other parts of the film). The care worker's use of these expressions does not sound like mocking but an echo of Lee's utterance, suggesting that the direction of communication is not only one way from care worker to the care receiver.

In excerpt (8) Lee chats with the same care worker as in (7).

(8) Immediate matters of daily life - Chatting [video clip 5] <https://doi .org/10.6o84/mg.figshare.13124483>

1 Lee: you're not even gonna stay with me?

2 CW1: later. < putting something away over a desk at a care worker station>

3 Lee: later?

4 CW1: yeah.

5 Lee: oh, what if THEY going away?

6 CW1: no, THEY'll be here. <facing Lee>

7 Lee: you sure?

8 Cw1: uh-huh $<$ nods $>$

9 Lee: oh $<$ Looking away $>$ 
$10<\ldots$ approx. $3 \mathrm{~s}><\mathrm{CW}$ is fixing Lee's earring $>$

11 Lee: what are you doing?

12 CW1: fixing your earring

13 Lee: oh I'm glad

14 CW1: hh

15 Lee: is it finished?

16 CW1: yes.

17 Lee: oh good. $<$ faces $\mathrm{CW}>$

$18 \quad<$ laughing >

The facial expressions and the sing-song intonation heard especially in lines 11-17 indicate the speakers' awareness of performing a routine conversation and especially Lee's enjoyment of the interaction, as confirmed by the laughter in line 18. From the point of view of transmission of denotational information, the exchange in lines $\mathbf{9 - 1 8}$ is superfluous as Lee and the care worker know what they are doing (as clearly evidenced in the video). The exchange is not factual information but is likely to be confirmation of interpersonal relation between them.

The pronoun they used by Lee in line 5 does not point to a clear antecedent in this segment of the film, but it is evident that the care worker understands correctly to whom Lee is referring to as she responds to Lee using the same pronoun. ${ }^{9}$ The care worker as the partner of the conversation uses the contextual and the background knowledge to achieve the construal of propositionally unclear utterance.

The next excerpt, (9), is an exchange between Lee and care workers at the dining room after a meal. Lee initiates the conversation with cw2 by pointing to the table that hasn't been cleared yet. Lee seems to pretend that the "mess" was made by someone else and then shows something hidden inside her jacket to invite a reaction from the worker. There is a scene earlier in the film in which Lee "steals" a small packet of cereal from the care worker station. It is apparent that she is being mischievous, playing an innocent with a straight face, and wanting to engage the workers in a playful conversation. The workers first look a little taken aback, but then quickly start smiling and giving the sort of responses that Lee probably wanted to instigate. The scene illustrates Lee's inclination to engage with people through her dry humor (and

9 It is possible that the care worker simply went along with Lee without clear understanding of the referent. After a repeated viewing of the film, the author (and a few others who viewed the film) began to sense that this they refers to the film crew members. In a Japanese equivalent, there would be no pronoun but left inexplicit. 
mischief) and her interactional ability to do so. Like (8), the purpose of the conversation is engagement in interpersonal relation, not the exchange of propositional content, as many daily conversations are regardless of speaker's cognitive conditions.

(9) Immediate matters of daily life - being mischievous [video clip 6] $<$ https://doi.org/10.6o84/mg.figshare.13124483>

1 Lee: <taps CW2's shoulder to get attention.>

2 CW2:yes?

3 Lee: a mess. < pointing to plates, cups, etc. with leftover food on a dining table>

4 CW2:you, is your mess. < pointing to the "mess," and looks at Lee>

5 Lee: oh no no not really=

6 CW2: =yes. <nodding and smiling, looking at Lee>

$7 \quad[\mathrm{oh}, \mathrm{it}$ is really yours.

8 Lee: $[\operatorname{ahhh}(\mathrm{xxx})$

9 Lee: o::h no=

10 CW2: $=0$ ::yeah=

11 CW3: $=$ it is yours

12 Lee: $=0$ ::h no < showing to CW2 and CW3 something hidden inside of her jacket>

13 CW3: < points to Lee $>$ ah $<$ smiles $>$

14 CW2: uh-oh <looking at what's shown>

15 Lee: I'm going, I-I-I'm going up [over here <walking away $>$

16 CW2: [I see, I see < pointing to Lee>

17 Lee: don't see, forget it, just forget it. <waving hands>

In these three excerpts of spontaneous conversations happening in daily situations, it is fair to say that Lee carries on verbal interactions that sound natural even for people without dementia. Daily conversations may seem unimportant as they do not convey much intellectual content, but it requires sound pragmatic competence to know which formulaic expressions should be used in what order and in what prosody in order to convey the affective and interpersonal intention of the speaker. This aspect of human communication is important although possibly undervalued in theoretical studies, and it is important that Lee, a person with middle stage Alzheimer's, retains the ability and is willing to use it. The conduct of the care workers in this film indicates their effort to understand Lee's behavior, which likely supports Lee's retention of such pragmatic capability. 


\subsection{Interaction among the Residents}

The film captures scenes, rarely discussed in studies, in which the residents at varied levels of dementia interact and communicate with one another while they share space for activities, meals, and relaxing. It is notable that the residents interact with one another and exchange meaningful messages verbally and nonverbally. That is, they appear to understand one another, regardless of whether or not people without dementia understand them.

In this section, we examine three excerpts that exemplify varied degrees of communicative interaction. The excerpt (10) depicts the complexity of emotion and personality that Lee holds through her comments about the residents and her interaction with two of her fellow residents. We also see different ways in which her fellow residents respond to her in the scene. Example (11) is a brief excerpt of a relatively long stretch of conversation held between two residents who appear to be at an earlier stage of dementia than many others. They are reminiscing about their past lives and their conversation runs smoothly. The excerpt (12) presents two residents, a man and a woman, who generally do not speak in the film. In this excerpt the man makes an extended effort to connect with the woman, who is at the same dining table, and asks whether she likes him. All three excerpts represent interactions that involve personal and interpersonal topics that closely relate to the speakers' past or current emotional lives.

Excerpt (10) below starts off with a scene in which Lee expresses her thoughts about her fellow residents, performing almost like a (self-)designated reporter, to someone who is off-screen, probably the filmmaker (and the film crew). The scene then moves on to Lee's interaction with other residents, interspersed with her comments about them. While some of her comments and behavior toward the fellow residents are kind (lines 6-8, 13-14), others are negative and even harsh (lines $2-5,9-14,18,20,25^{-29}$ ). Resident 1 is mostly asleep, but Lee and Resident 2 engage in an active interaction.

(10) Emotive verbal and nonverbal interaction: Lee's comments about the residents [video clip 7] <https://doi.org/10.6o84/mg.figshare.13124483>

$<$ Camera shows three residents sleeping in armchairs while Lee speaks to someone off-screen >

1 Lee: <talking to someone off-screen>

2 most of them that I have here I can't stand to be near them

3 <slowly turning to the area where the three residents are>

$4 \quad$ it's the truth (.)

$5 \quad$ it's any truth you want to take, but it's truth. 
$<$ Lee is now beside one of the female residents (RES1) who is sleeping in an armchair with a baby doll in hand. Lee touches and slightly lowers RES1's sleeves>

$<$ RES1 begins to open her eyes $>$

(2s)

6 Lee: hello $()<$. to RES1>

7 how are you? (..)

8 you wanna go THERE for now? (.)

$<$ same area>

9 it's hard (.) <shaking head, talking to someone off-screen>

$10<$ hand gesture pointing towards the direction of the residents in the scene>

11 they're sitting there (.)

12 and some are crying, and some are-(.)

13 you know, <points towards to another female resident (RES2) who is off-screen $>$

14 th-(.) she's she's she's the wonderful. <hand pointing to RES2>

$<$ RES2 is smiling and pointing to Lee $>$

$(2 \mathrm{~s})$

$<$ RES2 points at someone off-screen, smiling $>$

15 RES2: I love you @<smiling>

$16 \quad(2 s)$

17 [no-]

18 Lee: [you]-you don't love anybody $=<$ looks toward camera and then faces RES2>

19 RES2: =that's right@ < smiling>

20 Lee : yes, keep your mouth (.) shut

21 RES2: $()<$. inhales $>$

22 did [you see that?] $<$ still smiling $>$

23 Lee: [shut up] < pointing her finger at REs2's mouth>

24 RES2: she made me a-a-a-(.) beautiful, @@@@

$<$ Lee walks away from RES2 toward the camera, then turns around to face RES2>

25 Lee: just remember this there's not gonna be any of you around,

26 nobody there. < points to the general direction of RES2 and others $>$

27 RES2: <Crosses her arms across her chest, opens her mouth as if saying 'oh'> 
28 Lee: you'll just lie there and look at the $()<$. pointing toward the pictures on the wall $>$ the-(.) the table ${ }^{10}<$ waving her pointing hand, begins to walk away $>$

30 RES2: oh:: <briefly looks at the table>

$<$ Lee keeps walking away $>$

31 RES2: oh::

32

33

ah $(.)<$. Uncrosses her arms and looks down $>$

34 no soul (.)

35

poo-pupu-poo-pu (.) beep-beep

RES2 is far less eloquent than Lee and her reactions to Lee's comments are delayed at times, but her responses are interactionally meaningful. Her awareness is particularly well manifested in the last two lines 34-35, although only with a few words. She remarks on Lee's heartless comments and criticizes it by saying no soul in line 34. One can also judge that the response in line 35 is done in an interactionally relevant way (whereas there is no denotational content), inexplicitly denouncing Lee's assertion, and there may not have been a better way to express such feelings also among people without dementia.

There is a fine line between socially expected (or accepted/prescribed) behavioral standards (or etiquette) and pragmatic competence. Either discerning the social norms (e.g. wakimae in the sense of Ide 1989, etc.) or diverging from it (engendering "interactional/interpersonal implicature" as in Matsumoto 1988, 1989) indicates pragmatic competence based on negotiation of interactional relations. Some may consider the harshness of Lee's comments as a sign of her compromised social ability, yet it is clear that the pragmatics of the exchange between Lee and Resident 2 does not rely on calculation of the propositional content of the utterances but is better understood as an issue of expressing interpersonal understanding.

Example (11), below, is an excerpt of a conversation between two residents (RES3, RES4). RES4 relates that her husband dated her sister before their marriage. The conversation flows naturally with back channeling, expressions of surprise and agreement as also would be expected between people without dementia. RES3 even offers a supporting comment for RES4 in lines $15^{-16}$ ('but you know I've heard a lot about those things').

10 A table is located against the wall beneath the pictures. 
(11) Affective verbal and nonverbal interaction: Story about husband [video clip 8] <https://doi.org/10.6084/mg.figshare.13124483>

1 Res3: (tell me) about Roy.

2 RES4: well, Roy dated my sister.

3 RES3: <Looks at RES4> dated your sister

4 RES4: uh-huh

5 RES3: oh my.

6 RES4: but um,

7 that ended - you know?

8 and I don't kno- I mean my sister, <shrugs her shoulders>

9 uh was $()<$. small hand gesture $>$ she could care less.

10 'cause she had tons of boyfriends $<$ small chuckle $>=$

11 RES3: = <nods $>$ yeah, right.

12 RES4: and a (.) < shrugs her shoulders $>$

13 I don't know I don't know, (xxx) just

$14 \quad[().(\mathrm{xxx}) \mathrm{a}$

15 RES3: [but you know I've heard a lot about

$16 \quad()<$. outward hand gesture $>$ those things.

17 RES4: yeah.

Even including the so-called fuzzy reference, i.e. those things in line 16, which is often used as a convenient way to refer to a general idea at issue, the interaction here seems to be nothing less than a casual conversation between pragmatically competent friendly adults.

Example (12) below is from an interaction between two residents with limited verbal capabilities. ${ }^{11}$ In this scene, a male resident (RES5) is desperately trying to get the attention of a female resident (RES6), who sits at his dining table, so that he can ask her an important question of whether she likes him.

(12) Affective verbal and nonverbal interaction: “You like me?" [video clip 9] $<$ https://doi.org/10.6o84/mg.figshare.13124483>

1 RES5: hey, hey.

$2 \quad$ hey you like me? < pointing his body> (.) you like me? < pointing his body>

$3<$ taps repeatedly a glass with a knife, making a tinging sound >

4 RES6: <slowly looks up at RES5>

11 In another scene, RES5 does not speak but shows negative emotion to Lee through gestures. RES 6 seems to be always silent in the film. 
The scene of this table comes back a little later in the film, and we find that these two residents are smiling and holding hands. The verbal effort of RES5 was made for the interpersonal purpose. He was competent for the purpose and RES6 apparently understood the content of RES5's verbal and nonverbal conduct.

What we have observed in the three excerpts from interactions among the residents in this section illustrate that all of them seem to have had successful communication even when their abilities varied, apparently adjusting their communicative expectations and strategies accordingly. The types of exchanges were different - excerpt (10) was an interaction overlaid with emotion centering around Lee's view about other residents; excerpt (11) was a disclosure of a personally important relation in one's life; and (12) was about establishing affective relationship - but they all involved matters of affect and interpersonal relation. These observations concur with Ryan et al. (2005: 18) in that "individuals with dementia, even those who are in the more advanced stages, retain communicative competence and are active contributors to interpersonal relationships." This relational aspect of pragmatic competence was outside of the concern of the conventional pragmatic theories, but as was shown in section 2, it is also crucial in the structure and the use of the Japanese language.

\section{$5 \quad$ Conclusion}

Through the examination of interactions involving persons with dementia, this paper argued for an approach to pragmatics that would ensure inclusion of perspectives from a variety of languages and practices with geographical or cognitive variables, which may be perceived as atypical or perhaps deviant from the point of view of languages and theories that have been conventionally accepted. PRAGMATICS OF UNDERSTANDING advocates to pay attention to the local factors important to the language users and to seek plausible local principles underlying their practices.

The phenomena in Japanese language structure and practice that were referred to in this and previous papers illustrated that, while the conventional pragmatic theories have based their analysis of verbal interaction on factual and denotational information, interpersonal and textual/contextual information is essential in understanding the production and construal of Japanese verbal interaction. Analogously, a case study of conversations involving persons with Alzheimer's demonstrated that relational aspect of interaction was the key to understand their pragmatic competence. When the topic of the interaction was related to personally or contextually relevant matters, the 
speakers exhibited more stable communicative competence than topics that were less relevant in those terms.

The practices of the speakers of Japanese and those with dementia share the characteristic of not being very much consonant with conventionally assumed pragmatic principles. In the case of verbal behavior of persons with Alzheimer's, the discrepancies can be used on the diagnosis of the stage of the condition as claimed by clinical pragmatists. It can be hoped that pragmatics can go a step further than determining disability and can serve to elucidate and understand how people communicate, even with atypical cognitive conditions. Findings with the perspective of pragmatics of understanding can not only explain atypical communicative systems but also can shed light into important aspect of pragmatics and human communication, i.e. the relational aspect of interaction, which has not clearly been spotlighted in the conventional universal pragmatic theories.

Contrastive pragmatics encourages studies that do not explicitly or implicitly assume norms, standards or principles that should apply to all languages, or to all social groups that use a given language, or to all interactional situations in which a language is used. It can ultimately lead to a fuller understanding of verbal communication and offer a solid ground on which to build a pragmatics of understanding.

\section{Acknowledgments}

This paper is an extensively revised and expanded version of a paper "Looking through the glasses of Lee, a woman with Alzheimer's," which I presented at the fourth conference of the Corpora for Language and Aging Research (CLARe 4), which was held in February 27-March 1, 2019 in Helsinki, Finland. I am very grateful to the organizers and the audience of the conference for their helpful comments. Different versions of the paper were presented at the Stanford Humanities Center and the Center for Advanced Study in the Behavioral Sciences, and I greatly benefited from the comments I received in these occasions. My heartfelt gratitude goes to Scott Kirschenbaum, the director of a brilliant observational documentary film, who generously allowed me to use his film for my analyses presented in this paper. My sincere thanks also go to the editors of the journal for their encouragement and patience and to the anonymous reviewers for their useful comments. 


\section{References}

Ameka, Felix K. and Marina Terkourafi. 2019. What if ...? Imagining non-Western perspectives on pragmatic theory and practice. Journal of Pragmatics 145: 72-82.

Brundage, Shelley B. 1996. Comparison of proverb interpretations provided by righthemisphere-damaged adults and adults with probable dementia of the Alzheimer type. Clinical Aphasiology, 24: 215-231.

Brown, Penelope and Stephen C. Levinson. 1978. Universals in language usage: politeness phenomena. In: Goody, E.N. (Ed.), Questions and Politeness. Cambridge University Press, Cambridge, pp. 56-29o.

Brown, Penelope and Stephen C. Levinson. 1987. Politeness: Some Universals in Language Usage. Cambridge University Press, Cambridge.

Brownell, Hiram H. and Stringfellow, Andrew. 1999. 'Making requests: Illustrations of how right-hemisphere brain damage can affect discourse production', Brain \& Language, 68: 442-465.

Clancy, Patricia M. 1980. Referential choices in English and Japanese narrative discourse. In Chafe, Wallace L. (ed.) The Pear Stories: Cognitive, Cultural, and Linguistic Aspects of Narrative Production. 127-202. Norwood, NJ: ABLEX Publishing Corporation.

Cummings, Louise. 2017. Clinical pragmatics. In Huang, Yan (ed.) The Oxford Handbook of Pragmatics. 346-361. Oxford: Oxford University Press.

Dijkstra, Katinka, Michelle S. Bourgeois, Rebecca S. Allen, and Louis D. Burgio. 2004. Conversational coherence: discourse analysis of older adults with and without dementia. Journal of Neurolinguistics 17. 263-28.

Davis, Boyd H. 2005. So, you had two sisters, right? Functions for discourse. In Boyd H. Davis (ed.) Alzheimer Talk, Text and Context: Enhancing Communication. 128-145. New York: Palgrave McMillan.

Davis, Boyd H. and Cynthia Bernstein. 2005. In Boyd H. Davis (ed.) Alzheimer Talk, Text and Context: Enhancing Communication. 6o-86. New York: Palgrave McMillan.

Ellis, Donald G. 1996. Coherence patterns in Alzheimer's discourse. Communication Research. 23.4: 472-495.

Grice, H. Paul. 1975. Logic and conversation. In Cole, P. \& J. Morgan (eds.) Syntax and Semantics 3: Speech Acts. 41-58. New York: Academic Press.

Guendouzi, Jacqueline and Boyd H. Davis. 2013. Dementia discourse and pragmatics. In Davis, Boyd and Jacuqeline Guendouzi (eds.) Pragmatics in Dementia Discourse. 1-28. New Castle upon Tyne. Cambridge Scholars Publishing.

Hamilton, Heidi E. 1994. Conversations with an Alzheimer's Patient. Cambridge: Cambridge University Press. 
Haspelmath, Martin. 2001. The European linguistic area: Standard Average European. In: Martin Haspelmath, Ekkehard König, Wolfgang Oesterreicher and Wolfgang Raible (eds.), Language Typology and Language Universals. Sprachtypologie und sprachliche Universalien. Sprachtypologie und sprachliche Universalien: La typologie des langues et les universaux linguistiques: An International Handbook / Ein internationales Handbuch / Manuel international. 1492-1510. Berlin/New York: Walter de Gruyter.

Horn, Laurence R. and Gregory Ward (eds.) 2004. The Handbook of Pragmatics. Oxford: Blackwell Publishing.

Huang, Yan. 2017. Introduction: What is pragmatics? In Huang Yan (ed.) The Oxford Handbook of Pragmatics. 1-20. Oxford: Oxford University Press.

Ide, Sachiko. 1989. Formal forms and discernment: Two neglected aspects of linguistic politeness. Multilingua. 223-248.

Kádár, Dániel Z. and Michael Haugh. 2013. Understanding Politeness. Cambridge University Press.

Keenan, Elinor Ochs. 1976. The universality of conversational postulates. Language in society 5.1: $67-8$ o.

Kempler, Daniel (1984). Syntactic and symbolic abilities in Alzheimer's disease (Doctoral dissertation, University of California, Los Angeles - Linguistics).

Levinson, Stephen C. 2012. The original sin of cognitive science. Top. Cognit. Sci. 4 (3), 396-403.

Matsumoto, Yoshiko. 1988. Reexamination of the Universality of Face: Politeness phenomena in Japanese. Journal of Pragmatics 12. 403-426.

Matsumoto, Yoshiko. 1989. Politeness and Conversational Universals: Observations from Japanese. Multilingua. 207-221.

Matsumoto, Yoshiko. 1997. Noun-Modifying Constructions in Japanese: A Frame Semantic Approach. Amsterdam: John Benjamins Publishing.

Matsumoto, Yoshiko. 2003. Reply to Pizziconi, Journal of Pragmatics 35. 1515-1521.

Matsumoto, Yoshiko. 2011. Painful to Playful: Quotidian frames in the conversational discourse of older Japanese speakers," Language in Society 40:5. 591-616.

Matsumoto, Yoshiko. 2015. The Power of the Ordinary: Quotidian Framing as a Narrative Strategy," Journal of Pragmatics 86. 100-105.

Matsumoto, Yoshiko, Bernard Comrie and Peter Sells. 2017. Noun-Modifying Clause Constructions in Languages of Eurasia: Rethinking theoretical and geographical boundaries. Amsterdam: John Benjamins Publishing.

Perkins, Michael. 2007. Pragmatic Impairment. Cambridge: Cambridge University Press. 
Post, Stephen G. 200o. The concept of Alzheimer's disease in a hypercognitive society. In Whitehouse, P.J., K. Maurer, and J.F. Ballenger (eds.) Concepts of Alzheimer's disease: Biological, clinical and cultural perspectives. 245-256. Baltimore: Johns Hopkins University Press.

Ramanathan, Vai. 1997. Alzheimer Discourse: Some Sociolinguistic Dimensions. Mahwah, NJ: Lawrence Erlbaum Associates, Inc.

Ryan, Ellen Bouchard, Kerry Byrne, Hendrika Spykerman, and J.B. Orange. 2005. Evidencing Kitwood's personhood strategies: Conversation as care in dementia. In Boyd H. Davis (ed.) Alzheimer Talk, Text and Context: Enhancing Communication. 18-36. New York: Palgrave McMillan.

Ripich, Danielle N., Carpenter, Brian D., and Ziol, Elaine W. 20oo. Conversational cohesion patterns in men and women with Alzheimer's disease: A longitudinal study. International Journal of Language \& Communication Disorders. 35: 49-64.

Rosaldo, M.Z. 1982. The things we do with words: Ilongot speech acts and speech act theory in philosophy. Language in Society 11: 203-237.

Silverstein, Michael. 1976. Shifters, linguistic categories, and cultural description. Meaning in anthropology, 11-55.

Sperber, Dan and Deirdre Wilson. 1986. Relevance: Communication and Cognition. Oxford: Basil Blackwell.

Surian, Luca and Siegal, Michael. 2001. Sources of performance on theory of mind tasks in right-hemisphere-damaged patients. Brain \& Language, 78: 224-232.

Whorf, Benjamin Lee. 1956 [1941]. Language, Thought, and Reality: Selected writing of Benjamin Lee Whorf. (Edited by John B. Carroll). Cambridge, MA: M IT Press.

Wierzbicka, Anna. 1986. Does language reflect culture? Evidence from Australian English. Language in Society, 15(3) . 349-373.

Wierzbicka, Anna. 2014. Imprisoned in English. Oxford University Press, New York.

Wray, Alison. 2020. The dynamics of dementia communication. New York: Oxford University Press.

\section{Documentary Film}

Kirschenbaum, Scott. 2010. You're looking at me like I live here and I don't. 